\title{
Thermodynamic Assessment of the Pt-Sb System
}

\author{
Jinming Liu ${ }^{1 *}$, Yinghui Zhang ${ }^{1}$, Cuiping Guo ${ }^{2}$ \\ ${ }^{1}$ School of Material Science and Engineering, Jiangxi University of Science and Technology, Ganzhou, China \\ ${ }^{2}$ Department of Materials Science and Engineering, University of Science and Technology Beijing, Beijing, China \\ Email: 'liujm2011@sina.com
}

Received December 4, 2012; revised January 4, 2013; accepted January 15, 2013

Copyright (C) 2013 Jinming Liu et al. This is an open access article distributed under the Creative Commons Attribution License, which permits unrestricted use, distribution, and reproduction in any medium, provided the original work is properly cited.

\begin{abstract}
The Pt-Sb system was critically assessed by means of CALPHAD technique. Based on the experimental data in the literature, the excess Gibbs energies of the solution phases (liquid, rhombohedral, fcc) were modeled with the Redlich-Kister equation. The five intermetallic compounds, $\mathrm{Pt}_{7} \mathrm{Sb}, \mathrm{Pt}_{3} \mathrm{Sb}, \mathrm{Pt}_{3} \mathrm{Sb}_{2}, \mathrm{PtSb}$, and $\mathrm{PtSb}_{2}$ were treated as stochiometric compounds and expressed as the formula $(\mathrm{Pt})_{m}(\mathrm{Sb})_{n}$. The intermetallic compound, $\mathrm{Pt}_{5} \mathrm{Sb}_{\text {with a homogenerity }}$ ranges $0.155-0.189 \mathrm{Sb}$, were treated as the formula $(\mathrm{Pt}, \mathrm{Sb})_{m}(\mathrm{Pt}, \mathrm{Sb})_{n}$. A set of self-consistent thermodynamic parameters of the Pt-Sb system was obtained.
\end{abstract}

Keywords: Pt-Sb Phase Diagram; Thermodynamic Assessment; Thermodynamic Properties; CALPHAD Technique

\section{Introduction}

The precious metals, $\mathrm{Pt}, \mathrm{Sb}, \mathrm{Au}, \mathrm{Ag}$ and their alloys, have been widely applied as catalysts for their high thermal stability and high activity, such as decompounding hydrazine, purifying automobile gas, oxygenating selectively and so on [1-5]. Understanding the phase equilibria as well as the thermochemical behaviour of these systems is helpful for the development of the related materials. This paper intends to assess the $\mathrm{Pt}-\mathrm{Sb}$ system thermodynamically and provides a set of selfconsistent parameters for calculation of the phase equilibria and thermochemical properties of the system.

\section{Literature Review}

The Pt-Sb phase diagram consists of the liquid, the facecentered cubic (fcc), terminal solid solution (Pt); the terminal solid solution, rhombohedral $(\mathrm{Sb})$ with a negligible solubility of Pt. The gas phase was estimated by Itkin and Alcock [6], which is not considerated in the present work.

The liquidus was determined by thermal analysis in Refs. [7-10]. The liquidus in the Pt-Sb system was based mainly on the results made by Durussel and Feschotte [11] using differential thermal analysis (DTA), which was supported by the majority of the data [7-10].

In the $\mathrm{Pt}-\mathrm{Sb}$ system, there are six intermediate phases,

${ }^{*}$ Corresponding author.
$\mathrm{Pt}_{7} \mathrm{Sb}, \mathrm{Pt}_{5} \mathrm{Sb}, \mathrm{Pt}_{3} \mathrm{Sb}, \mathrm{Pt}_{3} \mathrm{Sb}_{2}, \mathrm{PtSb}$, and $\mathrm{PtSb}_{2}$. The $\mathrm{Pt}_{7} \mathrm{Sb}$ compound was discovered by [11], using DTA, microprobe analysis, and $\mathrm{X}$-ray powder (XRD). $\mathrm{Pt}_{7} \mathrm{Sb}$, a cubic structure, is formed by a peritectoid reaction. Different designations for the phase $\mathrm{Pt}_{5} \mathrm{Sb}$ are " $\mathrm{Pt}_{4} \mathrm{Sb}$ " [8], " $\mathrm{Pt}_{34} \mathrm{Sb}_{7}$ " [10], " $\mathrm{Pt}_{4+} \mathrm{Sb}$ " [12], and " $\mathrm{Pt}_{82} \mathrm{Sb}_{18}$ " [13]. A compound, "Pt $\mathrm{Sb}_{2}$ " was reported in Ref. [7] and not confirmed in other publications $[8,10,12,13]$. The compound as $\mathrm{Pt}_{5} \mathrm{Sb}$ has a cubic structure wth a homogeneity range of 0.155 to $0.189 \mathrm{Sb}$ [11]. The boundaries of the phase were determined using a temperature dependence of the lattice parameter. This phase is formed at $748^{\circ} \mathrm{C} \pm$ $4^{\circ} \mathrm{C}$ by peritectic reaction, which was consistent with Refs. [7-9]. It decomposed at $560^{\circ} \mathrm{C}$ by eutectoid reaction.

The compound $\mathrm{Pt}_{3} \mathrm{Sb}$ was formed by peritectic reaction $[9,11]$. The compound was investigated using thermal arrest by [8] and explained by the phase transformation in " $\mathrm{Pt}_{4} \mathrm{Sb}$ ". The compound $\mathrm{Pt}_{3} \mathrm{Sb}$ was examined and observed as a single phase with a composition of $0.275 \mathrm{Sb}$ and as a second phase at 0.25 and $0.30 \mathrm{Sb}$ by Srivastava et al. [14]. However, $\mathrm{Pt}_{3} \mathrm{Sb}$ was confirmed as a stoichiometric compound in subsequent research [10].

The compound $\mathrm{Pt}_{3} \mathrm{Sb}_{2}$ was determined by Bhan et al. [9] and confirmed by Kim [10]. It is formed by a peritectic reaction at $732^{\circ} \mathrm{C}[9]$ or $739^{\circ} \mathrm{C} \pm 4^{\circ} \mathrm{C}$ [11]. The compound $\mathrm{PtSb}$ was determined by several researchers and the formed temperature was different, $1045^{\circ} \mathrm{C}[7], 1040^{\circ} \mathrm{C}$ [8], $1043^{\circ} \mathrm{C}$ [9], and $1046^{\circ} \mathrm{C} \pm 3^{\circ} \mathrm{C}$ [11]. The composition of PtSb was determined by Refs. $[10,11,15,16]$. The re- 
sults of made by Durussel and Feschotte [11], Kim [10], and Kjekshus [17] showed that the composition of PtSb can be adopted as only approximately stoichiometric compound.

The compound $\mathrm{PtSb}_{2}$ was first found by chemical analysis of crystals precipitating from Pt-Sb melts containing an excess of $\mathrm{Sb}$ [18]. The temperature of congruent melting of $\mathrm{PtSb}_{2}$ was measured as $1226^{\circ} \mathrm{C}$ [7], $1210^{\circ} \mathrm{C}$ [8], and $1225^{\circ} \mathrm{C}$ [11]. The enthalpy increments of $\mathrm{PtSb}_{2}$ measured by drop calorimetry in the temperature interval $196^{\circ} \mathrm{C}$ to $620^{\circ} \mathrm{C}$ [19].

From the above literature [6-19], the present assessed Pt-Sb phase diagram consists of the liquid, the face-centered cubic $(\mathrm{fcc})$ terminal solid solution $(\mathrm{Pt})$, the terminal solid solution $(\mathrm{Sb})$ with a negligible solubility of $\mathrm{Pt}$ and six intermediate phases, $\mathrm{Pt}_{7} \mathrm{Sb}, \mathrm{Pt}_{5} \mathrm{Sb}, \mathrm{Pt}_{3} \mathrm{Sb}_{2} \mathrm{Pt}_{3} \mathrm{Sb}_{2}, \mathrm{PtSb}$ and $\mathrm{PtSb}_{2}$.

\section{Thermodynamic Models}

\subsection{Unary Phases}

The Gibbs energy function $G_{i}^{\phi}(T)=G_{i}^{\phi}(T)-H_{i}^{S E R}$ $(298.15 \mathrm{~K})$ for the element $i(i=\mathrm{Pt}, \mathrm{Sb})$ in the phase $\phi(\phi$ $=$ liquid, face-centered cubic(fcc) and rhombohedral) is described by an equation of the following form:

$$
\begin{aligned}
& G_{i}^{\phi}(T) \\
& =a+b T+c T \ln (T)+d T^{2}+e T^{3}+f T^{-1}+g T^{7}+h T^{-9}
\end{aligned}
$$

where $H_{i}^{\text {SER }}(298.15 \mathrm{~K})$ is the molar enthalpy of the element $i$ at $298.15 \mathrm{~K}$ in its standard element reference (SER) state, fcc for $\mathrm{Pt}$ and rhombohedral for $\mathrm{Sb}$. The Gibbs energy of the element $i, G_{i}^{\phi}(T)$, in its SER state, is denoted by $\mathrm{GHSER}_{i}$, i.e.,

$$
\begin{gathered}
\operatorname{GHSER}_{\mathrm{Pt}}={ }^{0} G_{\mathrm{Pt}}^{\mathrm{fcc}}(T)-H_{\mathrm{Pt}}^{\mathrm{SER}}(298.15 \mathrm{~K}) \\
\operatorname{GHSER}_{\mathrm{Sb}}={ }^{0} G_{\mathrm{Sb}}^{\mathrm{rhomb}}(T)-H_{\mathrm{Sb}}^{\mathrm{SER}}(298.15 \mathrm{~K})
\end{gathered}
$$

In the present work, the Gibbs energy functions are taken from the SGTE (Scientific Group Thermodata Europe) pure elements database compiled by Dinsdale [20].

\subsection{Solution Phases}

In the Pt-Sb system, there are three solution phases: liquid, fcc and rhombohedral. The gas phase was not considerated in the $\mathrm{Pt}-\mathrm{Sb}$ system, similar to the results re- ported by Durussel and Feschotte [11]. Their Gibbs energies are described by the following expression:

$$
\begin{aligned}
G_{m}^{\phi}= & x_{\mathrm{Pt}} G_{\mathrm{Pt}}^{\phi}(T)+x_{\mathrm{Sb}} G_{\mathrm{Sb}}^{\phi}(T) \\
& +R T\left(x_{\mathrm{Pt}} \ln x_{\mathrm{Pt}}+x_{\mathrm{Sb}} \ln x_{\mathrm{Sb}}\right)+{ }^{\mathrm{E}} G_{m}^{\phi}
\end{aligned}
$$

where $\mathrm{R}$ is the gas constant, $x_{\mathrm{Pt}}$ and $x_{\mathrm{Sb}}$ are the mole fraction of $\mathrm{Pt}$ and $\mathrm{Sb}$, respectively, and ${ }^{E} G_{m}^{\phi}$ is the excess Gibbs energy, expressed by the Redlich-Kister polynomial [21].

$$
{ }^{\mathrm{E}} G_{m}^{\phi}=x_{\mathrm{Pt}} x_{\mathrm{Sb}} \sum_{j}^{j} L^{\phi}\left(x_{\mathrm{Pt}}-x_{\mathrm{Sb}}\right)^{j}
$$

where ${ }^{j} L^{\phi}$ is the interaction parameter between element $\mathrm{Pt}$ and $\mathrm{Sb}$, which is to be evaluated in the present work. Its general form is

$$
L^{\phi}=a+b T+c T \ln (T)+d T^{2}+e T^{3}+f T^{-1}
$$

In most cases, only the first one or two terms are used according to the temperature dependence on the experimental data.

\subsection{Intermetallic Compounds}

There were six intermediate phases, $\mathrm{Pt}_{7} \mathrm{Sb}, \mathrm{Pt}_{5} \mathrm{Sb}_{2} \mathrm{Pt}_{3} \mathrm{Sb}$, $\mathrm{Pt}_{3} \mathrm{Sb}_{2}, \mathrm{PtSb}$, and $\mathrm{PtSb}_{2}$ in the Pt-Sb system. The phases crytal structure data was shown in Table 1. According to the composition and crystal structure data, the $\mathrm{Sb}$ in the five compounds, $\mathrm{Pt}_{7} \mathrm{Sb}, \mathrm{Pt}_{3} \mathrm{Sb}, \mathrm{Pt}_{3} \mathrm{Sb}_{2}, \mathrm{PtSb}$ and $\mathrm{PtSb}_{2}$ of the system with no or little solid solubility will be treated as the stoichiometric compounds. While the compound $\mathrm{Pt}_{5} \mathrm{Sb}$ with more homogenertiy ranges $0.155-0.189 \mathrm{Sb}$ will treated as solid solution compound.

So the $\mathrm{Pt}_{5} \mathrm{Sb}$ phase had a homogenertiy ranges, $0.155-0.189 \mathrm{Sb}$. The two-sublattice model, $(\mathrm{Pt}, \mathrm{Sb})_{0.833}$ $(\mathrm{Pt}, \mathrm{Sb})_{0.167}$ is used to describe this phase in the present work.

The parameters $y_{i}^{\prime}$ and $y_{i}^{\prime \prime}$ are the site fractions of $\mathrm{Pt}$ or $\mathrm{Sb}$ on the first and second sublattices, respectively; the parameter $G_{* ; *}^{\mathrm{Pt} \mathrm{Sb}}$ represents the Gibbs energies of the compound $\mathrm{Pt}_{5} \mathrm{Sb}$ when the first and second subletices are occupied by only one element $\mathrm{Pt}$ or $\mathrm{Sb}$, respectively, which are relative to the enthalpies of pure fcc for $\mathrm{Pt}$ and rhombohedral for $\mathrm{Sb}$ in their SER state; ${ }^{j} L_{\mathrm{Pt}, \mathrm{Sb} \text {; }}^{\mathrm{Pt}_{\mathrm{t}} \mathrm{Sb}}$ and ${ }^{j} L_{*: \mathrm{Pt}, \mathrm{Sb}}^{\mathrm{Pt} \mathrm{Sb}}$ represent the $j$ th interaction parameters $(j=$ 0 ) between the element $\mathrm{Pt}$ and $\mathrm{Sb}$ on the first and second sublattice, respectively.

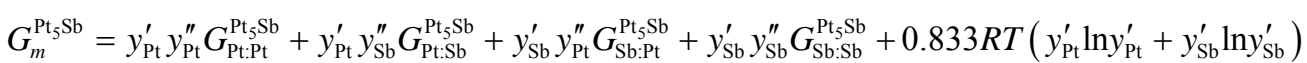

$$
\begin{aligned}
& +0.167 R T\left(y_{\mathrm{Pt}}^{\prime \prime} \ln y_{\mathrm{Pt}}^{\prime \prime}+y_{\mathrm{Sb}}^{\prime \prime} \ln y_{\mathrm{Sb}}^{\prime \prime}\right)+y_{\mathrm{Pt}}^{\prime} y_{\mathrm{Sb}}^{\prime}\left(y_{\mathrm{Pt}}^{\prime \prime} \sum_{j}^{j} L_{\mathrm{Pt}, \mathrm{Sb}: \mathrm{Pt}}^{\mathrm{Pt}}\left(y_{\mathrm{Pt}}^{\prime}-y_{\mathrm{Sb}}^{\prime}\right)^{j}+y_{\mathrm{Sb}}^{\prime \prime} \sum_{j}^{j} L_{\mathrm{Pt}, \mathrm{Sb}: \mathrm{Sb}}^{\mathrm{Pt}_{\mathrm{Sb}}}\left(y_{\mathrm{Pt}}^{\prime}-y_{\mathrm{Sb}}^{\prime}\right)^{j}\right) \\
& +y_{\mathrm{Pt}}^{\prime \prime} y_{\mathrm{Sb}}^{\prime \prime}\left(y_{\mathrm{Pt}}^{\prime} \sum_{j}^{j} L_{\mathrm{Pt} \mathrm{P}, \mathrm{Sb}}^{\mathrm{Pt}, \mathrm{Sb}}\left(y_{\mathrm{Pt}}^{\prime \prime}-y_{\mathrm{Sb}}^{\prime \prime}\right)^{j}+y_{\mathrm{Sb}}^{\prime} \sum_{j}^{j} L_{\mathrm{Sb}: \mathrm{Pt}, \mathrm{Sb}}^{\mathrm{Pt} \mathrm{Sb}}\left(y_{\mathrm{Pt}}^{\prime \prime}-y_{\mathrm{Sb}}^{\prime \prime}\right)^{j}\right)
\end{aligned}
$$


Table 1. Pt-Sb Crystal Structure Data.

\begin{tabular}{|c|c|c|c|c|c|c|}
\hline Phase & Composition, at $\% \mathrm{Sb}$ & Pearson symbol & Space group & $\begin{array}{l}\text { Strukturbericht } \\
\text { designation }\end{array}$ & Prototype & Refs. \\
\hline $\mathrm{Fcc}(\mathrm{Pt})$ & 0 to 10.4 & $c F 4$ & $F m \overline{3} m$ & $A 1$ & $\mathrm{Cu}$ & {$[22]$} \\
\hline $\mathrm{Pt}_{7} \mathrm{Sb}$ & 12.5 & cF32 & $F m \overline{3} m$ & $\ldots$ & $\mathrm{Ca}_{7} \mathrm{Ge}$ & [11] \\
\hline $\mathrm{Pt}_{5} \mathrm{Sb}$ & 15.5 to 18.9 & $c P 4$ & $F m \overline{3} m$ & $L 1_{2}$ & $\mathrm{AuCu}_{3}$ & {$[13]$} \\
\hline $\mathrm{Pt}_{3} \mathrm{Sb}$ & 25.0 & $t I 16$ & $I 4 / \mathrm{mmm}$ & $D 0_{23}$ & $\mathrm{Al}_{3} \mathrm{Zr}$ & [13] \\
\hline $\mathrm{Pt}_{3} \mathrm{Sb}_{2}$ & 40.0 & oI 20 & Ibam & $\ldots$ & $\ldots$ & [9] \\
\hline $\mathrm{PtSb}$ & 50.0 & $h P 4$ & $P 6_{3} / m m c$ & $B 8_{1}$ & NiAs & [23] \\
\hline $\mathrm{PtSb}_{2}$ & 66.7 & $c P 12$ & $\mathrm{~Pa} \overline{3}$ & $C 2$ & $\mathrm{FeS}_{2}$ (pyrite) & [24] \\
\hline Rhombohedral (Sb) & 100.0 & $h R 2$ & $R \overline{3} m$ & A7 & $\alpha$ As & {$[22]$} \\
\hline
\end{tabular}

The other intermediate phases, $\mathrm{Pt}_{7} \mathrm{Sb}, \mathrm{Pt}_{3} \mathrm{Sb}, \mathrm{Pt}_{3} \mathrm{Sb}_{2}$, $\mathrm{PtSb}$, and $\mathrm{PtSb}_{2}$ in the Pt-Sb system were treated as stochiometric compounds. The two-sublattice model, $(\mathrm{Pt})_{m}(\mathrm{Sb})_{n}$, is used to describe these phases in the present work. The Gibbs energy per mole of formula unit $(\mathrm{Pt})_{m}(\mathrm{Sb})_{n}$, was expressed as the following:

$$
G_{m}^{\mathrm{Pt}_{m} \mathrm{Sb}_{n}}=m \mathrm{GHSER}_{\mathrm{Pt}}+n \mathrm{GHSER}_{\mathrm{Sb}}+\Delta G_{f}^{\mathrm{Pt}_{m} \mathrm{Sb}_{n}}
$$

where $\Delta G_{f}^{\mathrm{Pt}_{m} \mathrm{Sb}_{n}}$ is the Gibbs energy of formation per mole of formula unit $\mathrm{Pt}_{m} \mathrm{Sb}_{n}$. And $\Delta G_{f}^{\mathrm{Pt}_{m} \mathrm{Sb}_{n}}$ can be given by the following expression:

$$
\Delta G_{f}^{\mathrm{Pt}_{m} \mathrm{Sb}_{n}}=a+b T
$$

where the parameters $a$ and $b$ were to be evaluated in the present work.

\section{Optimization}

Most of the above experimental information was selected for the evaluation of the thermodynamic model parameters. In the present work, the phase relation and transformation temperatures based on the phase diagram of the Pt-Sb system compiled by Itkin and Alcock [6], determinded by Bhan et al. [9], and Durussel and Feschotte [11].

The optimization was carried out by means of the Thermo-Calc software [25], which can handle various kinds of experimental data. The program works by minimizing an error sum where each of the selected data values is given a certain weight. The weight is chosen by personal judgment and changed by trial and error during the work until most of the selected experimental information is reproduced within the expected uncertainty limits.

The ways to get the phase diagram summarized as several steps using the Thermo-Calc software. Firstly, it is the Unary phases to get the GES file, which is the basis of the assessment. Secondly, it is the thermodynamic models of the solution phases and the compounds to form the TCM file. The expression of the thermodynamic model was shown in Section 3.

Last is the optimization. The optimization was carried out by means of the Thermo-Calc software based on the POP file to get the PAR file. The POP file was the phases equlibria, while the PAR file was the results of the optimization. When the phase diagram is successfully optimized, all the phases in the system will get a set of consistent thermodynamic parameters to express Gibbs energies. Using the set of consistent thermodynamic parameters to reproduce the phase diagram and build the database such as the TDB file.

\section{Results and Discussions}

A thermodynamic description of the Pt-Sb system obtained in the present work is shown in Table 2. The $\mathrm{Pt}-\mathrm{Sb}$ phase diagram calculated by means of the present thermodynamic parameters is presented in Figure 1, and nearly identical to the one determined by Bhan et al. [9], Durussel and Feschotte [11]. Because of the symmetry of liquid at both sides of the compound $\mathrm{PtSb}_{2}$, there is great different about the liquid at $0.20-0.40 \mathrm{Sb}$ between the calculated results and the experimental data [7-9].

The invariant equilibria of the Pt-Sb system are listed in Table 3. In the Table 3, some calculating data is nearly to experiment data but some is very different to experiment data. There is some reasons about these. The one is that the liquid at $0.20-0.40 \mathrm{Sb}$ is deeper than others. Other is that the liquid of the sides of $\mathrm{PtSb}_{2}$ is treated the symmetry during the assessed procedure. So it is very difficult to treat and optimize to get the same as the experimental data. In order not to change the types of reactions, the temperatures of reactions were revised in this work. As shown in the table, most satisfactory agreement is obtained between the calculations and experiments [7-9,11], where there is uncertainty in the invariant reaction temperature at $0.20-0.40 \mathrm{Sb}$. 
Table 2. Thermodynamic parameters of the Pt-Sb system ${ }^{\mathrm{a}}$.

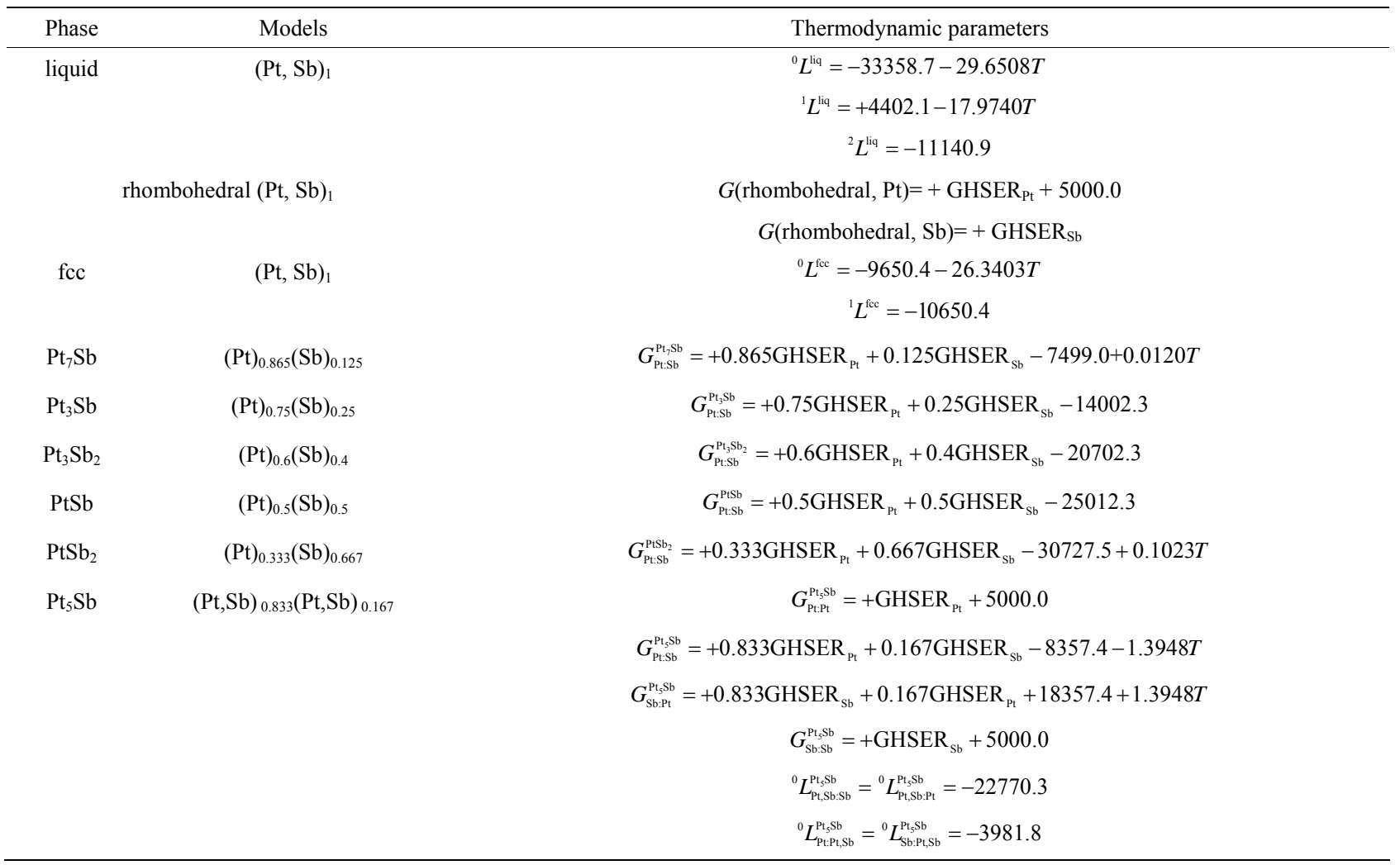

${ }^{\mathrm{a}}$ In $\mathrm{J} \cdot \mathrm{mole}^{-1}$ of the formula units.

Table 3. Invariant reactions of the Pt-Sb system.

\begin{tabular}{cccccc}
\hline Reaction & $T(\mathrm{~K})$ & & $x(\mathrm{Sb})$ & & References \\
\hline liq. $+\mathrm{fcc}(\mathrm{Pt}) \rightarrow \mathrm{Pt}_{5} \mathrm{Sb}$ & 1021 & 0.275 & 0.100 & 0.166 & {$[11]$} \\
& 1139 & 0.2775 & 0.1240 & 0.1652 & This work \\
fcc $+\mathrm{Pt}_{5} \mathrm{Sb} \rightarrow \mathrm{Pt}_{7} \mathrm{Sb}$ & 898 & 0.104 & 0.155 & 0.125 & {$[11]$} \\
& 898 & 0.0330 & 0.1441 & 0.1250 & This work \\
& 833 & 0.164 & 0.125 & 0.250 & {$[11]$} \\
$\mathrm{Pt}_{5} \mathrm{Sb} \rightarrow \mathrm{Pt}_{7} \mathrm{Sb}+\mathrm{Pt}_{3} \mathrm{Sb}$ & 833 & 0.1530 & 0.125 & 0.2500 & This work \\
& 948 & 0.302 & 0.189 & 0.250 & {$[11]$} \\
liq. $+\mathrm{Pt}_{5} \mathrm{Sb} \rightarrow \mathrm{Pt}_{3} \mathrm{Sb}$ & 1128 & 0.2844 & 0.1703 & 0.2500 & This work \\
& 903 & 0.315 & 0.250 & 0.400 & {$[9]$} \\
liq. $\rightarrow \mathrm{Pt}_{3} \mathrm{Sb}+\mathrm{Pt}_{3} \mathrm{Sb} b_{2}$ & 1127 & 0.2877 & 0.2500 & 0.4000 & This work \\
& 1012 & 0.352 & 0.500 & 0.400 & {$[9]$} \\
liq. $+\mathrm{PtSb} \rightarrow \mathrm{Pt}_{3} \mathrm{Sb}_{2}$ & 1133 & 0.2957 & 0.5000 & 0.4000 & This work \\
& 1319 & 0.475 & 0.667 & 0.500 & {$[8]$} \\
liq. $+\mathrm{PtSb}_{2} \rightarrow \mathrm{PtSb}$ & 1197 & 0.3485 & 0.6667 & 0.5000 & This work \\
& 1499 & 0.667 & 0.667 & - & {$[7]$} \\
liq. $\rightarrow \mathrm{PtSb}_{2}$ & 1497 & 0.667 & 0.667 & - & This work \\
& 899 & 0.990 & 0.667 & 1.000 & {$[11]$} \\
& 0.9974 & 0.6667 & 1.000 & This work \\
\hline $\mathrm{PtSb}_{2}+\mathrm{rhomb}$ & & & &
\end{tabular}

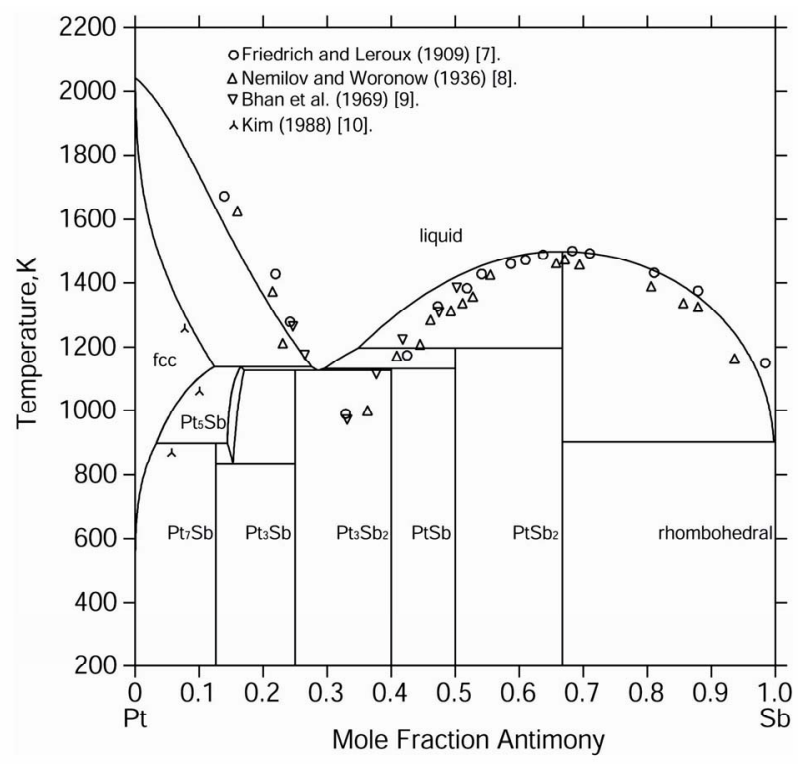

Figure 1. Calculated Pt-Sb phase diagram by the present thermodynamic escription with the experimental data measured by Friedrich and Leroux [7], Nemilov and Woronow [8], Bhan et al. [9] and Kim [10].

In view of the estimated experimental errors (about $0.01-0.02), 24$ of the 26 experimental invariant reaction compositions in the $\mathrm{Pt}-\mathrm{Sb}$ system are well reproduced. 


\section{Conclusion}

The phase relations and the thermodynamic description of the Pt-Sb system were critically evaluated from the experimental information available in the literature. A set of consistent thermodynamic parameters were derived. With the thermodynamic description available, one can now make various calculations of practical interest or in the optimization of high-order systems.

\section{Acknowledgements}

This work was supported by the National Natural Science Foundation of China (Nos. 50934011, 51264012) and Jiangxi University of Science and Technology Grade Scientific Research Project (No. jxxj12032).

\section{REFERENCES}

[1] L. W. Lin, T. Zhang, J. L. Zang and Z. S. Xu, "Dynamic Process of Carbon Deposition on Pt and Pt-Sn Catalysts for Alkane Dehydrogenation," Applied Catalysis, Vol. 67, No. 1, 1990, pp. 11-23. doi:10.1016/S0166-9834(00)84428-0

[2] A. Hinz, B. Nilsson and A. Andersson, "Simulation of Transients in Heterogeneous Catalysis: A Comparison of the Step- and Pulse-Transient Techniques for the Study of Hydrocarbon Oxidation on Metal Oxide Catalysts," Chemical Engineering Science, Vol. 55, No. 20, 2000, pp. 4385-4397.

[3] L. C. Li and Y. J. Lan, "Advance in the Catalysis for Hydrazine Decompositon," Industrial Catalysis, Vol. 2, No. 1, 1994, pp. 3-7. (in Chinese)

[4] S. Gao and L. D. Schmidt, "Effect of Oxidation-Reduction Cycling on $\mathrm{C}_{2} \mathrm{H}_{6}$ Hydrogenolysis: Comparison of $\mathrm{Ru}$, $\mathrm{Rh}, \mathrm{Ir}, \mathrm{Ni}, \mathrm{Pt}$, and $\mathrm{Pd}$ on $\mathrm{SiO}_{2}$," Journal of Catalysis, Vol. 115, No. 2, 1989, pp. 356-364.

[5] W. Chu, Q. G. Yan, X. Liu, Q. Li, Z. L. Yu and G. X. Xiong, "Rare Earth Promoted Nickel Catalysts for the Selective Oxidation of Natural Gas to Syngas," Studies in Surface Science and Catalysis, Vol. 119, 1998, pp. 855856. doi:10.1016/S0167-2991(98)80538-7

[6] V. P. Itkin and C. B. Alcock, "The Pt-Sb (PlatinumAntimony) System," Journal of Phase Equilibria, Vo. 17, No. 4, 1996, pp. 356-361.

[7] K. Friedrich and A. Leroux, "Melting Diagram for Alloys of Platinum with Antimony," Metallurgie, Vol. 6, 1909, pp. 1-3. (in German)

[8] W. A. Nemilov, N. M. Woronow and Z. Anorgm "Über Legierungen des Platins mit Antimon," Zeitschrift für anorganische und allgemeine Chemie, Vol. 226, No. 2, 1936, pp. 177-184. doi:10.1002/zaac.19362260211

[9] S. Bhan, T. Godecke, K. Schubert, "Konstitution Einiger Mischungen des Platins Mit b-Elementen $(\mathrm{B}=\mathrm{Sn}, \mathrm{Sb}$, Te)," Journal of the Less Common Metals, Vol. 19, No. 2, 1969, pp. 121-140. doi:10.1016/0022-5088(69)90027-7

[10] W.-S. Kim, "Phase Constitution of the Pt-Sb System," Journal of the Korean Institute of Metals, Vol. 26, 1988, pp. $378-384$.

[11] P. Durussel and P. Feschotte, "Les Systèmes Binaires Pd Sb et Pt Sb," Journal of Alloys and Compounds, Vol. 176, No. 1, 1991, pp. 173-181. doi:10.1016/0925-8388(91)90023-O

[12] S. Bhan, K. Schubert, "Über die Struktur von Phasen Mit Kupfer Unterstruktur in Einigen t-b Legierungen $(\mathrm{T}=\mathrm{Ni}$, $\mathrm{Pd}, \mathrm{Pt} ; \mathrm{B}=\mathrm{Ga}, \mathrm{In}, \mathrm{Tl}, \mathrm{Pb}, \mathrm{Sb}, \mathrm{Bi}$," Journal of the Less Common Metals, Vol. 17, No. 1, 1969, pp. 73-90. doi:10.1016/0022-5088(69)90038-1

[13] K. Schubert, S. Bhan, T. K. Biswas, K. Frank and E. K. Pandy, "Einige Strukturdaten Metallischer Phasen," Naturwissenschaften, Vol. 55, No. 11, 1968, pp. 542-543. doi:10.1007/BF00660131

[14] P. K. Srivastava, B. C. Giessen and N. J. Grant, "A Noncrystalline Pt-Sb Phase and Its Equilibration Kinetics," Metallurgical Transactions, Vol. 3, No. 4, 1972, pp. 977-988. doi:10.1007/BF02647675

[15] B. T. Mattias, "Superconducting Compounds of Nonsuperconducting Elements," Physical Review, Vol. 90, No. 3, 1953, p. 487. doi:10.1103/PhysRev.90.487

[16] A. Kjekshus and K. P. Walseth, "On the Properties of the $\mathrm{Cr}(1+\mathrm{x}) \mathrm{Sb}, \mathrm{Fe}(1+\mathrm{x}) \mathrm{Sb}, \mathrm{Co}(1+\mathrm{x}) \mathrm{Sb}, \mathrm{Ni}(1+\mathrm{x}) \mathrm{Sb}, \mathrm{Pd}(1+\mathrm{x})$ $\mathrm{Sb}$, and $\mathrm{Pt}(1+\mathrm{x}) \mathrm{Sb}$ Phases," Acta Chemica Scandinavica, Vol. 23, 1969, pp. 2621-2630. doi:10.3891/acta.chem.scand.23-2621

[17] A. Kjekshus, "Redetermined Lattice Constants of PtP2, PtAs2, PtSb2, and alpha-PtBi2," Acta Chemica Scandinavica, Vol. 14, 1960, pp. 1450-1451. doi:10.3891/acta.chem.scand.14-1450

[18] F. Roessler and Z. Anorg, "Synthese Einiger Erzmineralien und Analoger Metallverbindungen Durch Auflösen und Krystallisierenlassen DErselben in Geschmolzenen Metallen," Zeitschrift für Anorganische Chemie, Vol. 9, No. 1, 1895, pp. 31-77. doi:10.1002/zaac.18950090108

[19] E. M. Jaeger and T. J. Popema, "VIII. La Détermination Exacte des Chaleurs Spécifiques à des Températures Élevées: Sur la Règle Additive des Chaleurs Atomiques des Métaux Dans Leurs Combinaisons Binaires," Recueil des Travaux Chimiques des Pays-Bas, Vol. 55, No. 6, 1936, pp. 492-517. doi:10.1002/recl.19360550606

[20] A.T. Dinsdale, SGTE Pure elements (unary) database, version 4.5, 2006. (private Communication, Unpublished)

[21] O. Redlich and A. T. Kister, "Algebraic Representation of Thermodynamic Properties and the Classification of Solutions," Industrial \& Engineering Chemistry, Vol. 40, No. 2, 1948, pp. 345-347. doi:10.1021/ie50458a036

[22] Th. Massalski, "Binary Alloy Phase Diagrams," American Society for Metals , Metal Park, 1986.

[23] L. Thomassen, "Crystallization of Binary Compounds of Metals of Platinum Group II," Zeitschrift fur Physik B: Condensed Matter, Vol. 4, 1929, pp. 277-287.

[24] L. Thomassen, "Crystallization of Binary Compounds of Metals of Platinum Group," Zeitschrift fur Physik B: Condensed Matter, Vol. 2, 1929, pp. 349-379.

[25] B. Sundman, B. Jansson and J.-O. Andersson, "The Thermo-Calc Databank System," Calphad, Vol. 9, No. 2, 1985, pp. 153-190. doi:10.1016/0364-5916(85)90021-5 